\title{
APLIKASI TEKNIK DIFFUSIVE GRADIENT IN THIN FILM PADA PENENTUAN KONSENTRASI LOGAM BERAT MERKURI (Hg)
}

\section{[Application of Diffusive Gradient in Thin Film Techniques on Determination of Heavy Metal Concentration of Mercury $(\mathbf{H g})$ ]}

\author{
Khairuddin $^{{ }^{*}}$, Ruslan ${ }^{1}$ \\ 1) Jurusan Kimia, Fakultas MIPA, Universitas Tadulako \\ Jl. Soekarno Hatta Km. 9, Kampus Bumi Tadulako Tondo Palu, Telp. 0451- 422611 \\ *)Corresponding Author : heru_jns@yahoo.co.id (+62811457867)
}

Diterima 30 Maret 2018, Disetujui 25 April 2018

\begin{abstract}
High concentrations of $\mathrm{Hg}$ metal in the aquatic environment can lead to increased toxicity in the aquatic ecosystem. Therefore, the determination of the concentration distribution of heavy metals, such as mercury $(\mathrm{Hg})$ needs to be done. One of the most effective methods currently applied in determining $\mathrm{Hg}$ in aquatic environments is the Diffusive Gradient in Thin Films (DGT) technique. The objective of this research is to create and apply Diffusive Gradient in Thin Film technique on study of unstable mercury $(\mathrm{Hg})$ from the aquatic environment. This technique is a passive sampling method that can accumulate mercury labels $(\mathrm{Hg})$ located in the aquatic environment. The DGT device consists of a round plastic material with a diameter of $2.5 \mathrm{~cm}$ which can be filled with binding gel, polyacrylamide gel as diffusion layer gel, and a $0.45 \mu \mathrm{m}$ filter membrane. The results showed an increase in the amount of mass of mercury metal bound to the metal binding layer gel of $\mathrm{Hg}$ on the contact time variation. On the contrary, the result of the test with variation of gel thickness of the diffusion layer did not produce significant difference to the measurement of $\mathrm{Hg}$ mass attached to the binding gel. The application of DGT method on the determination of mercury metal concentration in Palu Bay waters measured within the range of 3.502 - $3.507 \mu \mathrm{g} / \mathrm{L}$.
\end{abstract}

Keywords: Mercury, DGT, Chelex-100, Polyacrylamide Diffusion Gel.

\begin{abstract}
ABSTRAK
Konsentrasi logam $\mathrm{Hg}$ yang tinggi di lingkungan akuatik dapat menyebabkan meningkatnya toksisitas dalam ekosistem air. Oleh karena itu, penentuan distribusi konsentrasi logam berat merkuri $(\mathrm{Hg})$ perlu dilakukan. Salah satu metode efektif yang saat ini digunakan dalam penentuan $\mathrm{Hg}$ di lingkungan akuatik adalah menggunakan teknik Diffusive Gradient in Thin Films (DGT). Tujuan penelitian ini adalah membuat dan mengaplikasikan teknik Diffusive Gradient in Thin Film pada kajian logam labil merkuri $(\mathrm{Hg})$ dari lingkungan perairan. Teknik ini merupakan metode passive sampling yang dapat mengakumulasi spesi labil merkuri $(\mathrm{Hg})$ yang berada di lingkungan akuatik. Perangkat DGT terdiri dari bahan plastik berbentuk bulat dengan diameter $2,5 \mathrm{~cm}$ yang dapat diisi dengan gel lapisan pengkelat logam, gel poliakrilamida sebagai gel lapisan difusi, serta membran filter $0,45 \mu \mathrm{m}$. Hasil penelitian menunjukkan peningkatan jumlah massa logam merkuri yang terikat pada gel lapisan pengikat logam $\mathrm{Hg}$ pada variasi waktu kontak. Sementara hasil pengujian dengan variasi ketebalan gel lapisan difusi tidak menghasilkan perbedaan yang signifikan terhadap pengukuran massa $\mathrm{Hg}$ yang terikat pada binding gel Aplikasi metode DGT pada penetapan konsentrasi logam merkuri dalam perairan Teluk Palu terukur pada kisaran 3,502 - 3,507 $\mu \mathrm{g} / \mathrm{L}$.
\end{abstract}

Kata Kunci: Merkuri, DGT, Chelex-100, Gel Difusi Poliakrilamida. 


\section{LATAR BELAKANG}

Unsur-unsur runut (trace elements) ditemukan dalam berbagai bentuk atau spesi kimia baik di air sungai maupun di air laut, berupa koloid, kompleks dengan bahan organik terlarut (dissolved organic matter), kompleks anorganik dan ion-ion bebas. Setiap bentuk atau spesi tersebut memiliko perbedaan dalam bioavailability dan toksisitas. Bioavailability dan toksisitas dari spesi ion tembaga, seng, kadmium $\left(\mathrm{Zn}^{2+}, \mathrm{Cu}^{2+}, \mathrm{Cd}^{2+}\right)$ terhadap organisme air jauh lebih tinggi dibandingkan apabila unsur tersebut membentuk kompleks dengan bahan organik terlarut, atau koloid atau bahkan partikel lainnya. Tetapi, tidak semua unsur runut logam berlaku teori tersebut. Sebagai contoh untuk logam merkuri dan timbal apabila terbentuk proses metilasi maka toksisitas kedua kompleks ini akan jauh lebih tinggi bila dibandingkan dalam keadaan ion bebas. Logam berat di dalam air laut juga akan terakumulasi dalam sedimen dan biota laut melaui proses gravitasi, biokonsentrasi, bioakumulasi dan biomagnifikasi oleh biota laut (Junaedi et al., 2002).

Kadar logam berat dalam perairan yang mengalami akumulasi secara terus menerus akan mengakibatkan kadar logam berat dalam tubuh biota juga ikut meningkat dan berujung pada terjadinya pencemaran. Variasi spesi logam telah diidentifikasi pada perairan alami termasuk bentuk spesi organik dan anorganik dan sangat tergantung pada konsentrasi logam, kekuatan ion maupun $\mathrm{pH}$. Merkuri merupakan salah satu logam dalam sistem perairan dan dijumpai baik sebagai ion bebas maupun dalam bentuk kompleks dengan bahan organik terlarut. Logam ini penting dimonitoring dalam sistem perairan karena mudah menjadi toksik pada tingkatan $10-50$ dari konsentrasi normal yang dibutuhkan untuk pertumbuhan organisme dan biota air (Cattani et al., 2008 dan Clarisse et al., 2012).

Oleh karena pencemaran di perairan akibat logam berat tersebut tidak dapat dibiarkan begitu saja, maka perlu dilakukan monitoring dan pengukuran kadar logam berat di lingkungan khususnya pada lingkungan perairan walaupun pengukuran logam runut dalam sistem perairan relatif sulit untuk dilakukan (Dahlqvist et al., 2002). Logam berat $\mathrm{Hg}$ adalah salah satu polutan perairan yang telah banyak diteliti dengan berbagai metode pengukuran, salah satunya ialah metode DGT (Diffusive Gradient in Thin Film) secara in situ. Spesi labil di lingkungan akuatik dapat dengan mudah diukur dengan metode DGT (Gao, 2012). Keuntungan dari teknik DGT jika dibandingkan teknik konvensional, yaitu konsentrasi logam berat dalam setiap sentimeter atau milimeter kedalaman sedimen dapat ditentukan karena memiliki resolusi spasial yang tinggi.

Prinsip dasar metode DGT yaitu spesi analit berdifusi melalui suatu hidrogel dan terikat pada binding gel atau 
adsorben, kemudian konsentrasi analit diketahui setelah dielusikan dengan suatu asam. Kelebihan dari metode ini meliputi rataan konsentrasi solut dapat diketahui selama waktu tertentu, prekonsentrasi dapat dilakukan tanpa merusak sampel, dan sampel terkontaminasi dapat dikurangi. Zhang dan Davidson, (1995) menambahkan bahwa metode ini dapat memprediksi bioavailabilitas suatu logam labil, sulfat, dan fosfat karena konsentrasi spesi analit terikat binding gel diasumsikan sama dengan konsentrasi yang berdifusi dari perairam ke biota. Logam di dalam sedimen berdifusi melalui diffusive gel dan terakumulasi pada lapisan binding gel yang mengandung resin chelex sehingga logam tidak mengalami perubahan kimia hingga dianalisis. Selain itu, fraksinasi logam juga terjadi secara in situ sehingga perubahan sifat kimia tidak terjadi (Nurhamiddin dan Zam Zam, 2013). Fraksi logam yang mudah terlarut dan tertukar (dari fase padat sedimen ke air pori sedimen) akan terukur pada teknik DGT, seperti ion logam bebas atau komplek logam berukuran kecil. Poiliakrilamida digunakan sebagai binding gel pada sistem DGT karena telah diketahui memiliki kapasitas interaksi yang lebih baik. (Dunn et al., 2010).

DGT tersusun dari perangkat alat sederhana berbentuk bulat dengan diameter $2,5 \mathrm{~cm}$ berbahan plastik yang berisi lapisan pengkelat logam dan hidrogel sebagai lapisan difusi serta membran filter $0,45 \mu \mathrm{m}$. Hidrogel dapat berupa senyawa hidrofilik seperti poliakrilamida dengan jaringan tiga dimensi. Ketika sepenuhnya terhidrasi, hidrogel dapat terisi lebih dari 95\% air. Hidrogel yang kaya akan gugus-gugus polar juga memiliki kapasitas untuk difusi yang terkendali, respon pembengkakan (swelling) terhadap perubahan suhu, $\mathrm{pH}$, konsentrasi ion, dan kemampuannya untuk berinteraksi dengan logam berat (misalnya $\mathrm{Cd}, \mathrm{Pb}, \mathrm{Cr}, \mathrm{Hg}$ ) (Scally et al., 2006).

Logam berat dalam air laut dapat berupa logam terlarut ataupun tersuspensi yang dapat dipisahkan menggunakan membran filter berpori $0,45 \mu \mathrm{m}$. Filter membran adalah salah satu lapisan pada perangkat DGT selain dua lapisan lainnya (gel lapisan pengkelat logam dan gel lapisan difusi) yang berfungsi untuk memisahkan partikel tersuspensi pada peristiwa difusi (Fan et al., 2009). Ion logam berdifusi melalui filter membran dengan cara pembentukan gradien konsentrasi yang konstan sehingga terkumpul pada lapisan pengkelat yang yang selanjutnya diukur secara kuantitatif. Massa logam pada lapisan pengkelat diukur setelah dielusi dengan larutan asam.

Analit berdifusi dari larutan sampel melalui lapisan difusi kemudian diadsorbsi pada lapisan pengikat. Dengan demikian gradien konsentrasi pada lapisan difusi hingga konsentrasinya sama dengan konsentrasi pada larutan sampel. Massa 
logam dikumpulkan oleh gel resin (Chelex100) dari larutan logam menurut persamaan (1).

$$
\mathrm{C}=\frac{M \cdot \Delta g}{D \cdot t \cdot A}
$$

di mana $C$ adalah konsentrasi logam dalam bulk solusi, M massa logam dalam gel resin Chelex, $\Delta \mathrm{g}$ ketebalan lapisan difusi, D koefisien difusi ion logam dalam lapisan difusi, t waktu kontak dan A luas permukaan kontak.

Massa logam dikumpulkan oleh resin Chelex dihitung setelah elusi resin dalam $\mathrm{HNO}_{3} 1 \mathrm{M}$ menurut persamaan (2).

$$
\mathrm{M}=\frac{c_{e}\left(\mathrm{~V}_{g}+\mathrm{V}_{e}\right)}{f_{e}}
$$

dimana $C_{e}$ adalah konsentrasi logam dalam eluen, $V_{g}$ dan $V_{e}$ masing-masing volume gel resin dan eluen, dan $f_{e}$ adalah faktor elusi. Teknik DGT memberikan informasi yang berguna tentang berbagai jenis logam termasuk logam merkuri.

\section{METODE PENELITIAN}

\section{Bahan dan Peralatan}

Resin Chelex-100, Amonium persulfat $\quad\left(\mathrm{NH}_{4} \mathrm{~S}_{2} \mathrm{O}_{8}\right), \quad \mathrm{N}, \mathrm{N}, \mathrm{N}^{\prime} \mathrm{N}^{\prime}-$ Tetrametiletilendiamina (TEMED), membran selulosa nitrat $0,45 \mu \mathrm{m}, \mathrm{NaNO}_{3}$, $\mathrm{HNO}_{3}$. Peralatan penelitian berupa perangkat DGT (DGT Research Lancaster University, Inggris), mikrometer (jangka sorong).

\section{Prosedur Penelitian}

\section{Penyiapan Gel}

\section{a. Gel Poliakrilamida}

Pembuatan gel difusi ion permeabel mengikuti prosedur yang digunakan oleh
Zhang dan Davidson (1995). Larutan gel disiapkan melalui pencampuran akrilamida $15 \%$ dan cross-linker agarosa 0,3\%. Polimerisasi dimulai dengan menambahkan $7 \mu \mathrm{L}$ amonium persulfat dan $2,5 \mu \mathrm{L}$ tetrametiletilendiamina (TEMED) per mililiter larutan gel. Larutan gel yang dihasilkan lalu diletakkan pada cetakan kaca dan dipanaskan dalam oven pada temperatur $40^{\circ} \mathrm{C}$ selama 45 menit. Setelah dikeluarkan, gel dihidrasi dengan selama 24 jam untuk membuat gel menjadi stabil. Gel kemudian dicetak menggunakan pencetak (disc cutter) dengan diameter $2,5 \mathrm{~cm}$.

\section{b. Gel Resin Chelex-100}

Resin gel dibuat dari larutan gel dengan komposisi yang sama pada gel poliakrilamida. Sebanyak 0,2 g Chelex100 ditambahkan permililiter larutan gel. Kecepatan polimerisasi diturunkan dengan menambahkan $6 \mu \mathrm{L}$ amonium persulfat dan $2 \mu \mathrm{L}$ TEMED permililiter larutan gel untuk memungkinkan pengendapan resin di salah satu sisi gel. Gel kemudian dicetak menggunakan pencetak (disc cutter) dengan diameter $2,5 \mathrm{~cm}$ kemudian disimpan dalam 0,01 $\mathrm{M} \mathrm{NaNO}_{3}$.

\section{Pengujian Kinerja Teknik DGT}

\section{a. Pengaruh Waktu Kontak}

Perangkat DGT diisi dengan gel resin Chelex-100, gel difusi lalu ditutup dengan filter membran 0,45 $\mu \mathrm{m}$. Pengujian dilakukan melalui penggelaran sambil diaduk menggunakan $100 \mu \mathrm{g} / \mathrm{L}$ larutan $\mathrm{Hg}$ dalam $0,01 \mathrm{M} \mathrm{NaNO}_{3}$ dengan 
variasi waktu 2, 4, 6, dan 8 jam. Pada setiap variasi waktu penggelaran, resin gel dalam perangkat DGT diambil dari larutan kemudian dielusi dengan $2 \mathrm{~mL} \mathrm{HNO}_{3} 1 \mathrm{M}$ dan kadar logam $\mathrm{Hg}$ dalam resin diukur dengan AAS-Cold Vapour.

\section{b. Pengaruh Ketebalan Lapisan Difusi}

Hukum pertama Fick menunjukkan adanya ketergantungan linier antara akumulasi massa logam dalam resin dengan ketebalan gel difusi. Gel difusi poliakrilamida dengan tiga ketebalan $(0,40$ $\mathrm{mm}, 0,80 \mathrm{~mm}$ dan $1,20 \mathrm{~mm}$ ) digunakan untuk penelitian ini. Ke dalam perangkat DGT dipasang gel resin Chelex-100, gel difusi poliakrilamida dengan ketebalan yang berbeda digelar dalam larutan $\mathrm{Hg}$ $100 \mu \mathrm{g} / \mathrm{L}$ dalam $\mathrm{NaNO}_{3} \quad 0,01 \quad \mathrm{M}$ menggunakan waktu optimum percobaan sebelumnya. Setelah penggelaran selesai, fasa pengkelat logam gel resin DGT dipisahkan dari perangkat DGT, kemudian gel resin diekstraksi dengan $2 \mathrm{~mL} \mathrm{HNO}_{3} 1$ $\mathrm{M}$ dan kadar logam $\mathrm{Hg}$ diukur dengan AAS-Cold Vapour.

\section{Aplikasi Pada Air Laut}

Air laut disampling dari tiga titik dengan metode gabungan waktu (composite samples) yang dimana campuran contoh-contoh sesaat yang diambil dari satu lokasi pada waktu yang berbeda. Sampel air tersebut disaring dengan kertas saring lalu diambil $800 \mathrm{~mL}$ yang ditempatkan pada beaker glass 1000 $\mathrm{mL}$. Sampel lalu ditambahkan (spiked) larutan baku $\mathrm{Hg}^{2+}$ masing-masing $5 \mathrm{mg} / \mathrm{L}$.
Perangkat DGT yang telah disusun sesuai urutannya, dimasukkan pada sampel air laut yang akan diuji. Setelah itu gel resin dielusi dalam $3 \mathrm{~mL}$ larutan $\mathrm{HNO}_{3} 1 \mathrm{M}$ selama 24 jam. Setelah itu, diambil alikuot hasil elusi $\mathrm{HNO}_{3} 1 \mathrm{~mL}$ dan diencerkan hingga $10 \mathrm{~mL}$. Kemudian diukur dengan menggunakan AAS-Cold Vapour sehingga dapat diketahui konsentrasi $\mathrm{Hg}^{2+}$ dalam masing-masing unit DGT.

\section{HASIL DAN PEMBAHASAN}

\section{Gel Difusif dan Gel Resin}

Pembuatan gel difusif poliakrilamida dengan pengikat silang N,N'Methylenebisacrylamide (MBA) didasarkan pada reaksi adisi polimerisasi radikal bebas (Chrambach, 1985). Pada pembuataan diffusive gel dengan menggunakan MBA digunakan inisiator ammonium persulfat dan TEMED (N,N,N'N'-Tetraetilendiamin) sebagai katalisnya. Proses polimerisasi akrilamida menjadi gel difusi poliakrilamida dimulai dengan adanya amonium per sulfat yang bertindak sebagai inisiator. Kehadiran TEMED dapat mempercepat laju pembentukan radikal bebas amonium persulfat dan mengkatalisis proses polimerisasi. Radikal bebas amonium persulfat mengkonversi monomer akrilamida menjadi ion radikal bebas sehingga dapat bereaksi dengan monomer akrilamida yang belum teraktivasi untuk terjadinya reaksi polimerisasi berantai.

Sebagai lapisan gel pengkelat 
logam merkuri Chelex terdiri dari kopolimer stiren divinilbenzena yang memiliki gugus asam iminodiasetat sehingga dapat bertindak sebagai ion pengkelat dalam mengikat kation polivalen.

\section{Perangkat DGT}

Untuk mengaplikasikan DGT pada larutan $\mathrm{Hg}$ dengan menggunakan resin gel, hal pertama yang dilakukan adalah menyiapkan unit DGT yaitu dengan cara meletakkan gel resin dan difusi gel yang telah dicetak, serta membran selulosa nitrat yang telah direndam dalam akuademin dengan susunan seperti pada Gambar 1.

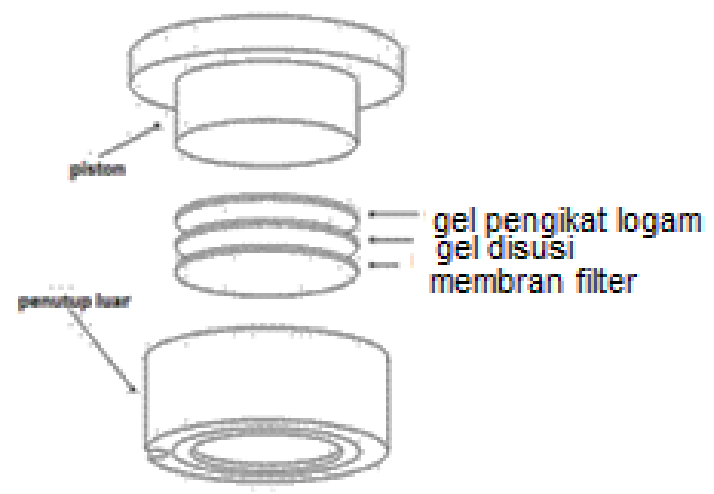

Gambar 1 Susunan filter membran $0,45 \mu \mathrm{m}$, gel lapisan difusi, dan lapisan pengkelat logam dalam probe DGT

\section{Kinerja Gel Difusi Poliakrilamida}

Uji kinerja resin dalam larutan $\mathrm{Hg}$ ini bertujuan untuk mengetahui apakah resin gel yang telah dibuat benar-benar mampu menyerap ion logam $\mathrm{Hg}$ dan mengetahui apakah dalam jangka waktu tertentu massa logam yang terserap pada resin chelex masih memberikan serapan linier atau sudah mencapai konstan. Pada
Gambar 3 terlihat bahwa massa logam $\mathrm{Hg}$ yang terserap dalam resin semakin meningkat seiring dengan pertambahan waktu hingga waktu 8 jam.

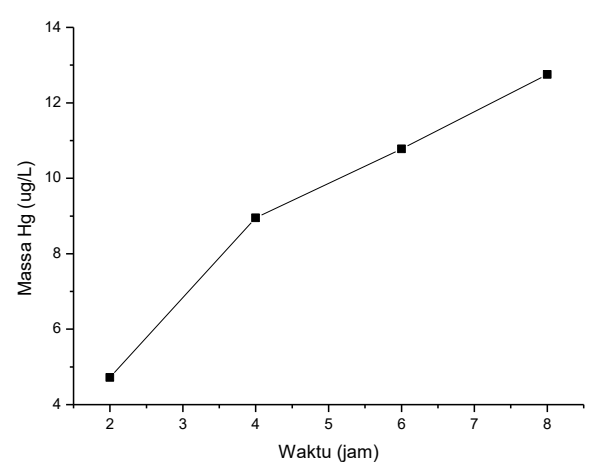

Gambar 2 Grafik massa $\mathrm{Hg}$ dalam resin Chelex yang diperoleh pada variasi waktu

\section{Kinerja Gel Difusi}

Penentuan nilai koefisien difusi bertujuan untuk menentukan seberapa cepat $\mathrm{Hg}$ mampu melewati lapisan gel difusif. Koefisien difusi (D) dihitung dengan memplot kurva waktu vs jumlah massa dalam lapisan pengkelat. Kemiringan (k) dapat dinyatakan sebagai:

$$
\mathrm{k}=\frac{D \cdot t \cdot A}{\Delta g}
$$

Dari persaman ini, koefisien difusi, D, $\left(\mathrm{mm}^{\urcorner 2} \mathrm{~s}^{-1}\right)$ dapat dihitung :

$$
\mathrm{D}=\frac{k \cdot \Delta g}{A \cdot t}
$$

Dimana $\mathrm{A}\left(\mathrm{mm}^{2}\right)$ adalah luas area gel, $\Delta \mathrm{g}$ $(\mathrm{mm})$ adalah ketebalan gel, $\mathrm{t}$ adalah lama waktu kontak (detik). Slope (k) ditentukan dari kurva regresi waktu vs massa.

Koefisien difusi merkuri dalam gel poliakrilamida hasil perhitungan diperoleh $8,97 \times 10-6 \mathrm{~cm}^{2} \mathrm{~s}^{-1}$. untuk Chelex-100. 
Hasil pengujian massa $\mathrm{Hg}$ dalam binding gel dengan gel difusif tebal $0,40 \mathrm{~mm}, 0,80$ $\mathrm{mm}$, dan 1,0 $\mathrm{mm}$ meningkat dengan bertambahnya waktu kontak (Gambar 3).

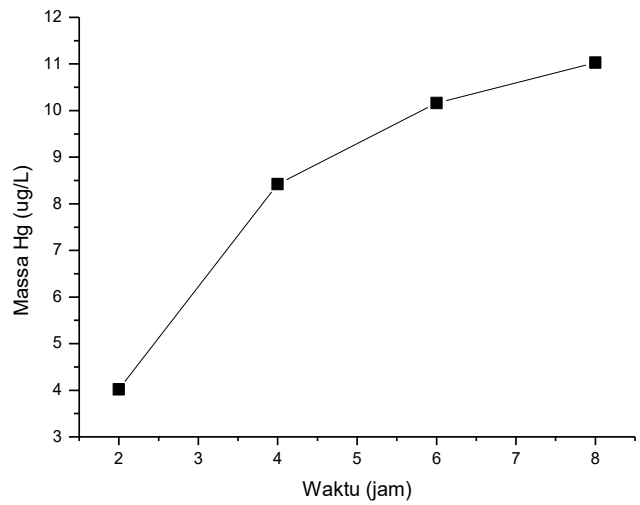

(a)

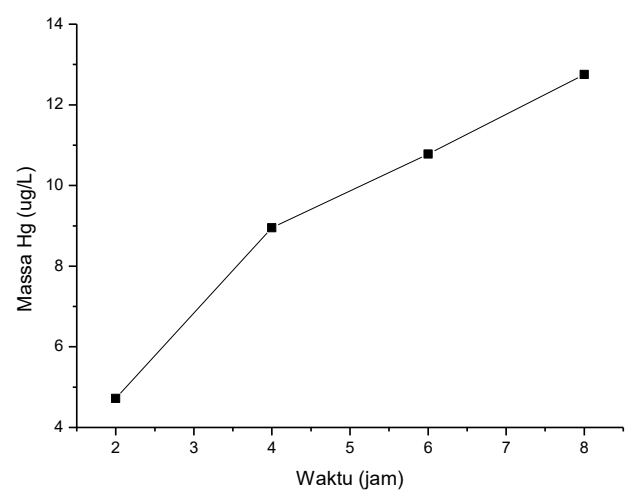

(b)

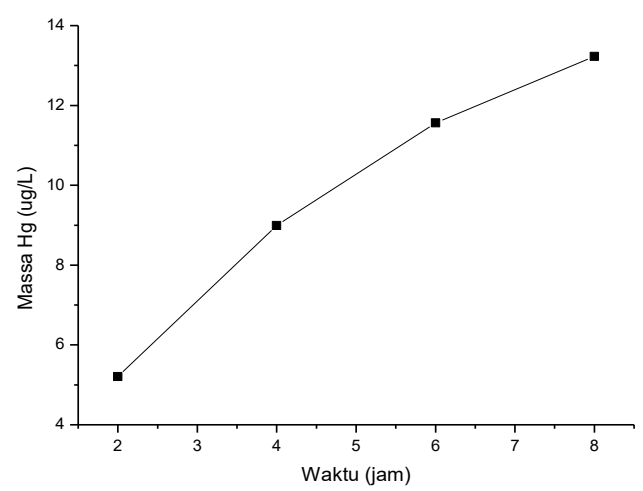

(c)

Gambar 3 Grafik massa $\mathrm{Hg}$ dalam gel Chelex-100 dengan gel difusif (a) tebal $0,40 \mathrm{~mm}$, (b) $0,80 \mathrm{~mm}$, dan (c) $1,0 \mathrm{~mm}$ yang diperoleh pada variasi waktu.
Data hasil perbandingan $\mathrm{C}_{\mathrm{DG}}$ pada pengukuran massa $\mathrm{Hg}$ pada berbagai ketebalan lapisan difusif poliakrilamidamenunjukkan hasil yang relatif sama, artinya ketebalan lapisan difusif $0,4 \mathrm{~mm}-1,0 \mathrm{~mm}$ relatif baik dalam aplikasi pada penentuan konsentrasi $\mathrm{Hg}$ dengan metode DGT.

\section{Aplikasi Pada Air Laut Teluk Palu}

Untuk mengetahui keandalan metode analisis, teknik DGT telah diaplikasikan untuk mengetahui konsentrasi logam merkuri pada air laut perairan Teluk Palu. Chelex-100 dengan ketebalan $0,80 \mathrm{~mm}$ digunakan pada perangkat DGT. Konsentrasi logam merkuri dalam empat stasiun lokasi sampel air laut yang diukur melalui aplikasi DGT dengan resin gel Chelex-100 dan gel difusi poliakrilamida diperoleh kadar $\mathrm{Hg}:$ 3,502 - 3,507 $\mu \mathrm{g} / \mathrm{L}$.

\section{KESIMPULAN}

Air laut Teluk Palu pada lokasi penelitian mampu mensuplai analit $\mathrm{Hg}$ kedalam air pori sehingga sejumlah fluks massa analit $\mathrm{Hg}$ bermigrasi ke probe DGT. Konsentrasi Hg dalam air laut Teluk Palu diukur dengan metode DGT dengan lapisan resin Chelex-100 dan gel difusi poliakrilamida berada pada kisaran 3,502 $3,507 \mu \mathrm{g} / \mathrm{L}$.

\section{DAFTAR PUSTAKA}

Cattani, I., Spalla, S., Beone, G. M., Del Re, A. A. M., Boccelli, R., \& Trevisan, M. (2008). Characterization of mercury species in soils by HPLC-ICP-MS and 
measurement of fraction removed by diffusive gradient in thin films. Talanta, 74(5), 1520-1526.

Clarisse, O., Lotufo, G.R., Hintelmann, H., Best, E.P.H. (2012). Biomonitoring and assessment of monomethylmercury exposure in aqueous systems using the DGT technique. Science of the Total Environment. 416: 449-454.

Chrambach, A. (1985). The Practice of Quantitative Gel Electrophoresis. Weinheim: VCH, Deerfield Beach.

Dahlqvist, R., Zhang, H., Ingri, J., \& Davison, W. (2002). Performance of the diffusive gradients in thin films technique for measuring $\mathrm{Ca}$ and $\mathrm{Mg}$ in freshwater. Analytica Chimica Acta, 460(2), 247-256.

Junaedi, E. et al. (1999). Penentuan Kapasitas Pengompleks Tembaga dan Konstanta Stabilitas Kondisional dalam Air Sungai dengan Metode Anodic Tripping Voltametry, Prosiding Seminar Nasional Kimia V. Yogyakarta: Jurusan Kimia FMIPA UGM. hlm $55-60$.

Dunn, R. J. K., Teasdale, P. R., Warnken, J., Jordan, M. A., \& Arthur, J. M. (2007). Evaluation of the in situ, time-integrated DGT technique by monitoring changes in heavy metal concentrations in estuarine waters. Environmental Pollution, 148(1), 213-220.
Fan, H., Sun, T., Li, W., Sui, D., Jin, S., \& Lian, X. (2009). Sodium polyacrylate as a binding agent in diffusive gradients in thin-films technique for the measurement of $\mathrm{Cu} 2+$ and $\mathrm{Cd} 2+$ in waters. Talanta, 79(5), 12281232.

Gao, Y., De Canck, E., Leermakers, M., Baeyens, W., \& Van Der Voort, P. (2011). Synthesized mercaptopropyl nanoporous resins in DGT probes for determining dissolved mercury concentrations. Talanta, 87, 262267.

Nurhamiddin, F., \& Zam Zam, Z. (2013). Distribusi Konsentrasi Logam Berat (Cu dan Cd) Pada Sedimen Sungai Menggunakan Teknik Diffusive Gradient In Thin Film, J. Tek. Ling. 14(2).

Scally, S., Davison, W., Zhang, H. (2006). Diffusion coefficients of metals and metal complexes in hydrogels used in diffusive gradients in thin films, Analytica Chimica Acta. 558: 222229.

Zhang, H., \& Davidson, W. (1995). Performance characteristics of diffusion gradients in thin films for the in situ measurement of trace metals in aqueous solution. Anal. Chem. 67:3391-4000. 